\title{
"AS PALAVRAS E AS COISAS": UMA NOTA SOBRE A TERMINOLOGIA DOS ESTUDOS CONTEMPORÂNEOS DE TRABALHO
}

\author{
Paula Marcelino ${ }^{1}$
}

\section{Resumo}

Não é possível passar pela literatura sobre as questões do trabalho sem se deparar com os termos "flexibilização" e "precarização". A esses, outros dois se associam: "trabalho atípico" e "desregulamentação". Nosso objetivo com este texto é fazer uma breve reflexão sobre quais desses termos consideramos adequados para a análise das relações de emprego e trabalho sob o capitalismo contemporâneo e explicitar de quais processos falamos quando os usamos. Este texto está baseado em pesquisa bibliográfica dos estudos da área de trabalho.

Palavras-chave: Flexibilização. Precarização. Desregulamentação. Trabalho atípico.

\section{“WORDS AND THINGS": A NOTE ABOUT CONTEMPORARY LABOR STUDIES TERMINOLOGY}

\begin{abstract}
It is impossible go through the literature on the issues of work without encountering the terms «flexibilization» and «precarization» and two others associated with them: «atypical work» and «deregulation». Our objective is to ponderwhich of these terms we consider suitable for the analysis of employment relations and work

${ }^{1}$ Professora do Departamento de Sociologia da Universidade de São Paulo. Doutora em Ciências Sociais pela Unicamp.prpmarcelino@gmail.com
\end{abstract}


under contemporary capitalism and explain which processes we are talking about when we use them. This text is based on bibliographical studies in the field of labor.

Keywords: Flexibilization. Precarization. Deregulation. Atypical work.

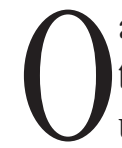
artigo que ora iniciamos pretende ser um breve debate sobre quatro termos frequentemente presente nos estudos da área de trabalho da última década: "flexibilização", "precarização", "desregulamentação" e "trabalho atípico". Esse debate tem como objetivo estabelecer os parâmetros para a utilização ou não desses termos para definir e caracterizar eventos concretos vivenciados pelos trabalhadores contemporaneamente.

Dentre os quatro termos elencados, talvez "flexibilização" seja o que tem maior penetração nas análises das ciências sociais. Aparentemente mais neutro, ele pode ser encontrado desde os textos da área de Administração - Pagnoncelli (1993), Oliveira (1994), Martins (2005) - até a literatura de inspiração marxista, em especial a partir dos anos 1980. Lallement (2000) faz uma análise da categoria "flexibilidade" e afirma que se trata de uma palavra sem equivalente na física, na que se fala em elasticidade dos materiais. Para o autor, o termo flexibilidade comporta em si práticas tão numerosas quanto contraditórias. Ele pode fazer referência, por exemplo, ao trabalho precário (o que ele chama de flexibilidade quantitativa) ou ao desenvolvimento da polivalência em benefício da força de trabalho estável no seio das empresas (a flexibilidade qualitativa).

Esse argumento pressupõe uma tese presente, de maneiras distintas, numa parte considerável da bibliografia sobre o tema - Coriat (1994), Fleury (1993), Arbix (1996), Leite (2000), entre outros - qual seja, a tese de que novos padrões produtivos trazem benefícios para a força de trabalho. Especialmente nos primeiros anos de implantação dos métodos japoneses, o modelo de flexibilização de maior impacto nas empresas, as análises partiam do entendimento de que a direção do processo de trabalho era algo em disputa. Isto por algumas características específicas das novas formas de gestão do processo e das relações de trabalho e emprego: a) a necessidade de participação dos trabalhadores com sugestões de aperfeiçoamento das etapas de produção; b) a variação salarial de acordo com a produção; c) a diminuição dos postos de hierarquia dentro das empresas; d) a necessidade da polivalência dos trabalhadores.

A crítica aos novos padrões de produção considerados flexíveis foi amplamente feita por Gounet (1999), Antunes (1999), Braga (1996), Druck 
(1999), Linhárt, Rist e Durand (2002) e Araújo (2007), entre muitos outros. Com algumas diferenças entre os autores, destaca-se em comum o questionamento da autonomia, da possibilidade de real iniciativa e dos demais benefícios que, em tese, a organização flexível do processo de trabalho poderia trazer aos trabalhadores. Os vários estudos de caso disponíveis sobre os impactos dessas transformações parecem corroborar que a implementação dos chamados "métodos flexíveis" de produção significaram a ampliação da exploração dos trabalhadores, com consenquente queda na qualidade das relações dentro e fora dos ambientes de trabalho.

Entretanto, se por trás da definição de flexibilização de Lallement está uma idéia de fundo que pode ser questionada - a possibilidade de maior autonomia ou, no limite, de controle por parte da força de trabalho sobre o processo de trabalho -, parece-nos que o autor acerta quando aponta que o termo "flexibilidade" se refere a movimentos que podem ser opostos, com sentidos diferentes e, por vezes, contraditórios. Contrapostos à idéia de autonomia e maior controle dos trabalhadores, está, no léxico geral da área de trabalho, a flexibilidade como: diminuição (part time não desejado pelo trabalhador) ou ampliação (em horas não regulares) da jornada de trabalho, quebra de antigas proteções trabalhistas, jornada de trabalho mutável (com banco de horas, por exemplo), contratos de trabalho precarizados, alterações na legislação da previdência social, introdução de novas formas de produzir que exijam dos trabalhadores envolvimento e participação nos objetivos da empresa, incorporação de novas tecnologias, etc. Ou seja, flexibilização pode significar quase todas as alterações ocorridas na organização produtiva e nas relações trabalhistas do início da década de 1970 até hoje.

A amplitude de fenômenos aos quais se faz referência quando se fala de "trabalho flexível" não é o único problema do termo. De maneira geral, na língua portuguesa, o termo flexibilidade tem uma conotação positiva, associada à possibilidade de adaptação à mudança, à aptidão para variadas atividades, à destreza e agilidade. Não por acaso as mudanças nos processos de trabalho e na legislação trabalhista são feitas sob o signo da flexibilização; o termo faz parte do jogo ideológico necessário para obter dos trabalhadores a colaboração necessária ao bom andamento dos processos produtivos e das relações de trabalho e emprego "flexibilizados". Isto quer dizer: denominar todos esses processos como flexíveis é esconder seu caráter de classe, de exploração do trabalho; é deixar de dizer a quem serve as mudanças em curso nas relações de trabalho e, principalmente, nas relações formais de emprego. 
Segundo Nanteiul (2002), não há um termo neutro para definir flexibilidade. Esse termo é indissociável das projeções normativas que marcam sua emergência histórica nos anos 1980, na empresa "reencantada", que promove a maleabilidade institucional e o ataque jurídico às proteções e direitos trabalhistas como o leque das soluções para a crise de desemprego, fazendo da empresa o lugar da anulação dos conflitos de classes e de interesses.

Nanteiul (2002), entretanto, mantém o uso do termo flexibilidade. Tal como esse autor, entendemos que é possível falar em flexibilidade para traduzir as mudanças dos principais mecanismos produtivos fordistas: da produção em massa, do one best way organizacional e das regras de empregos estáveis e homogêneas². Nanteiul, assim como Lallement (2000), trabalha com uma subdivisão da flexibilidade para explicar os atuais processos e relações de trabalho ao analisar a realidade francesa. Entretanto, distingue- se desse último autor quando se trata da análise das relações entre trabalhadores e empregadores, pois, nesse caso, Nanteiul entende que flexibilidade é sempre sinônimo de precarização do trabalho:

Havendo recurso ao emprego precário ou externalizando segmentos do aparelho produtivo, a flexibilidade externa conduz a uma redução drástica dos rendimentos, das proteções sociais e das possibilidades de integração social. Contudo, ela não é acompanhada, necessariamente, por uma degradação homogênea das condições de trabalho. Já a flexibilidade interna se traduz por uma reorganização dos tempos profissionais e pela evolução dos modos de coordenação internos. Mas esse movimento é acompanhado, igualmente, de uma desestabilização dos coletivos existentes e de uma intensificação do trabalho. Além disso, ele atinge tanto precários quanto estáveis (NANTEIUL, 2002, p. 65).

Nanteiul associa, portanto, o termo "flexibilização", quando se refere às relações empregatícias, ao de "precarização do trabalho". Esse mesmo autor acredita ser necessária, hoje, a distinção entre precariedade do emprego (fim ou enfraquecimento das proteções sociais ao trabalho) e precariedade do trabalho (condições que, independentemente do estatuto do trabalhador, geram sofrimento: intensificação do ritmo de trabalho, pressões por cumprimento de metas, etc.). $\mathrm{Na}$ nossa compreensão, a realidade brasileira aponta que precariedade do emprego e precariedade do trabalho podem, e vêm, associadas. E assim a trataremos ao longo

\footnotetext{
${ }^{2}$ Não há no texto de Nanteiul (2002) uma relativização do alcance do tipo de contrato de trabalho, uma referência ao fato, por exemplo, de extensas partes do globo nem terem chegado a experimentá-lo.
} 
deste artigo, pois, embora possam se referir a processos analiticamente distintos, a precarização do trabalho e do emprego são parte de um mesmo movimento que, em última instância é o da intensificação da exploração da força de trabalho.

Ambiguidade e desempenho de uma função ideológica junto aos trabalhadores; esses são os dois motivos pelos quais consideramos que classificar as formas de trabalho hoje como "flexíveis" é incorrer numa armadilha analítica, fundamentalmente, no que se refere às condições de trabalho e emprego. Os dados e reflexões de Lima (1998), Martins (2005), Krein (2007) e outros autores críticos dos processos que já citamos nos oferecem um panorama do que se considera trabalho flexível no Brasil e que, na nossa compreensão, reforçam a idéia de que quando se fala em "flexibilidade do trabalho" o que está em jogo, na verdade, é um processo de "precarização" das condições de trabalho e de emprego. Portanto, esse é o termo adequado prática e teoricamente. Segundo Lima (1998, p. 2):

A flexibilização das relações de trabalho pressupõe a eliminação de entraves à contratação e demissão de pessoal, assim como a redução de gastos com direitos sociais: recolhimento de impostos para previdência social, assistência médica etc. A discussão sobre a flexibilização tem como referência o welfarestate, o estado providência do capitalismo avançado, dominante na Europa Ocidental e América do Norte até a década de 80 com elevada proteção social aos trabalhadores e forte presença sindical. No Brasil, a discussão sobre flexibilização parte do princípio de que existe uma rigidez na legislação que não corresponde à realidade.

A citação acima nos oferece os principais elementos para a compreensão do processo de precarização pelo qual passa o trabalho no Brasil. Mesmo com um dos menores custos com a força de trabalho entre as nações do capitalismo industrial, eles são vistos pelos setores empresariais como fatores negativos na competição, responsáveis por um encarecimento desnecessário do preço do trabalho ${ }^{3}$. Uma grande ofensiva para modificar a legislação de forma a eliminar esses entraves ao processo de acumulação está em curso, em ritmo e intensidade variada, nos

\footnotetext{
3 O salário mínimo brasileiro ( $\mathrm{R} \$ 545,00$, em fevereiro de 2011) está muito aquém da necessidade relativa do trabalhador: "0 salário mínimo pago no Brasil deveria ser [no mesmo período] de $\mathrm{R} \$ 2.227,53$, de acordo com cálculos do Departamento Intersindical de Estatística e Estudos Socioeconômicos (Dieese). Este valor, que leva em consideração o custo da cesta básica de alimentos em dezembro, é o mínimo necessário para atender às considerações presentes na Constituição no que se refere a alimentação, moradia, saúde, educação, vestuário, higiene, transporte, lazer e previdência, segundo a entidade." (LORENZO, 2011).
} 
anos neoliberais; basicamente, desde Fernando Collor de Melo na presidência da república em $1990 .^{4}$

Nesse processo de redução dos direitos sociais, desenha-se uma nova forma de contratação, cujo caráter da "flexibilidade" não deixa dúvidas sobre o seu sentido: do ponto de vista do trabalhador, não há positividade. Os contratos flexíveis são, segundo Krein (2007), alternativas ao contrato padrão de emprego (estandard employment relationship) predominantes no pós-guerras, cujas características principais eram: centralização das negociações; reconhecimento dos sindicatos; restrições à dispensa de pessoal; subcontratação ou emprego de pessoal eventual; controle sindical sobre alocação das tarefas e procedimentos de promoção dos trabalhadores; formulação de políticas salariais de longo prazo com incorporação de parte dos ganhos de produtividade, jornada padrão de 8 horas; sistema de proteção em caso de doença, desemprego e velhice e o desenvolvimento de políticas sociais que permitiam a elevação indireta dos salários (KREIN, 2007, p. 104).

Muitos autores além de Krein (ANTUNES, 1999; BIHR, 1999; NANTEUIL, 2002; VASAPOLLO, 2005), apontam a existência de um contrato de trabalho típico, que eles definem como próprio do padrão de produção fordista ${ }^{5}$. Nesses casos, o contrato com prazo indeterminado é a regra básica - no Brasil, também o fato do trabalhador que o possui ter sua "carteira de trabalho assinada". Tal contrato também "se caracteriza pelo trabalho em tempo integral, com um único empregador, relativa estabilidade e remuneração fixa e mensal, tendo relação com o tempo de permanência no emprego e a formação profissional e dando uma perspectiva de carreira e de segurança." (KREIN, 2007, p. 107). Embora essas condições do contrato e seu alcance para o conjunto dos trabalhadores brasileiros possam ser relativizados, não é impróprio afirmar que também em nosso país essa foi a forma de contrato cristalizada pelo direito do trabalho, conquistada pelas lutas dos trabalhadores e consolidada com o desenvolvimentismo, com o processo de urbanização e industrialização do país.

Diante do exposto, não vemos grandes problemas no uso do termo "trabalho atípico" para definir aquelas formas de contrato ou trabalho que não se inserem nos moldes do padrão "contrato por tempo indeterminado, com carteira

\footnotetext{
${ }^{4}$ Para uma discussão sobre as fases do neoliberalismo brasileiro, destacamos dois autores que guardam diferenças entre si: Filgueiras (2006) e Sallum Junior. (1999).

${ }^{5}$ Para esses autores, o fordismo é mais que uma forma de organização da produção. 0 termo é usado para todo um período histórico, entre o pós-guerra e o início da década de 1970, e abarca, inclusive, as suas características econômicas e políticas, a forma de intervenção social do Estado e o tipo de regulamentação dos direitos trabalhistas.
} 
assinada, jornada regular e por tempo integral". No entanto, especialmente no caso do Brasil, o uso do termo "trabalho atípico" deve estar claramente associado à comparação com esse tipo de contrato. Isto porque, se a condição geral da maioria dos trabalhadores for pensada em termos numéricos, talvez não haja uma tipicidade (temporal e geográfica) do contrato com essas características nem no auge do período desenvolvimentista, e muito menos nesses tempos de reestruturação produtiva e de neoliberalismo. Típico, hoje, é ser precarizado. Trabalho típico e atípico nos parece, portanto, termos cujos sentidos tendem a se perder na medida em que nos afastamos historicamente do referencial fábrica fodista/estado desenvolvimentista ou de bem-estar.

Krein (2007) faz uma distinção que nos parece importante entre as formas de contratação atípicas e regimes especiais de trabalho. No seu entendimento, os regimes especiais de trabalho sempre existiram para mulheres, aprendizes, portadores de deficiências, portuários, entre outros. 0 que caracterizaria os regimes especiais de trabalho seria o fato de que eles se vinculariam a determinadas categorias de trabalhadores ou a modalidades de trabalho. 0 trabalho atípico, diferentemente, seria uma forma de contratação colocada à disposição no mercado geral de trabalho. Assim,

A novidade é que as novas formas de contratação atípicas têm como finalidade modificar o postulado do padrão anterior ou escapar de sua regulação, na perspectiva de reduzir os custos e ampliar a liberdade de a empresa contratar e despedir o empregado. São tipos de contratos que permitem a adaptação das empresas às flutuações econômicas, dispensando compromissos permanentes e custos com os seus empregados (KREIN, 2007, p. 108).

Os novos contratos atípicos, que ganharam força no Brasil a partir do início da década de 1990, têm objetivos distintos, segundo Krein. Primeiramente, servem aos governos como forma de legitimar a difusão do desemprego, colocando a responsabilidade no mercado de trabalho ao invés de assumir que este é fruto de uma determinada política econômica. Em segundo lugar, atende a uma imposição do funcionamento da empresa capitalista no sentido de redefinição do padrão das relações de trabalho - nas quais se incluem, como já afirmamos, as relações de emprego -, cuja "lógica é criar 'incentivos' para as empresas contratarem, por meio da redução de custos e de facilidades de despedir." (KREIN, 2007, p. 109). Abaixo, faremos uma lista das principais características desses contratos chamados atípicos ou flexíveis - para alguns autores - e que nós denominamos "precarizados" seguindo as informações fornecidas por Krein (2007, p. 109-110): 
1. Os contratos a termo, denominados por ele de "atípicos", têm as seguintes particularidades do ponto de vista dos direitos trabalhistas e da proteção social: a pré-determinação do prazo de vigência do contrato exclui qualquer tipo de estabilidade. Assim, os trabalhadores contratados sob essas modalidades não têm direito às estabilidades provisórias previstas no ordenamento jurídico, tais como a estabilidade da gestante, a decorrente de acidente de trabalho ou de doença profissional e a estabilidade assegurada ao dirigente sindical. As estabilidades obedecem ao período de vigência do contrato.

2. Como o tempo de duração do contrato é, em tese, acordado entre trabalhador e empregador, este fica desobrigado de pagar o adicional de $40 \%$ incidente sobre os depósitos ao FGTS (Fundo de Garantia por Tempo de Serviço), em caso de dispensa do trabalhador.

3. 0 trabalhador também não tem direito ao seguro desemprego, pois não há demissão.

4. Os trabalhadores temporários, em grande parte dos acordos coletivos, não têm direito à PLR (Participação nos Lucros e Resultados) ou, então, recebem uma parcela menor deste benefício.

5. 0 direito ao gozo das férias fica limitado e sujeito a dificuldades. Um exemplo disso é a sucessão de contratos - no caso do trabalho temporário/prazo determinado - que não permite acúmulo de tempo de trabalho no mesmo empregador suficiente para férias anuais.

6. Na maioria dos contratos a termo, ou temporários, o trabalhador tem dificuldade de assegurar o direito à aposentadoria por tempo de contribuição, dada a volatilidade da relação.

Conclui Krein que os trabalhadores submetidos a qualquer dessas modalidades de contratação apresentam uma situação mais vulnerável e inferiorizada no mercado de trabalho por disporem de um conjunto menor de direitos e proteções. Portanto, seus empregos são mais precários. Alguns exemplos dessa nova forma de contrato são: contrato de safra, o contrato temporário, o do primeiro emprego, o parcial, o contrato aprendiz, o trabalho voluntário (que não chega a ter contrato, na maior parte das vezes) e os contratados por tempo determinado.

A terceirização, em tese, pode ou não ser classificada como "trabalho atípico" a depender da forma de contrato que é estabelecida entre a contratante, a empresa subcontratada e o trabalhador. Os diversos estudos sobre 0 tema Marcelino (2004, 2008), Druck (1999), Druck e Borges (2002), Amorim (2003), Cavalcante (2009), Pochaman (2007), entre outros - mostram que, em nosso 
país, a terceirização é usada como instrumento de redução dos custos com a força de trabalho e implicam em precarização das relações de trabalho e das condições do emprego.

Segundo levantamento de Krein (2007, p. 112), a chamada contratação atípica teve um crescimento bastante significativo nos últimos anos: 158,6\% entre 1995 e 2005; número esse bem superior ao do contrato por prazo indeterminado (38,8\%). Na década de 1990, o crescimento do número de contratos por prazo indeterminado tem um saldo negativo de $-1,1 \%$. 0 mesmo movimento se observa no serviço público: "enquanto o número de servidores estatutários cresceu 21,2\%, o dos não-efetivos e dos temporários cresceu 67,4\%, no mesmo período, sem incluir no cálculo os terceirizados" (KREIN, 2007, p. 118).

Segundo Krein, uma das primeiras medidas de precarização dos contratos de trabalho foi a implementação da liberdade do empregador de demitir um funcionário sem a necessidade de justificativa ao trabalhador ou a qualquer órgão público. Isso acontece com a quebra da estabilidade para trabalhadores com mais de dez anos no mesmo emprego, permitida pela instituição do FGTS (Fundo de Garantia por Tempo de Serviço) através da Lei complementar nº 5.107 de 13 de setembro de 1966. Obrigado apenas a pagar multas rescisórias e indenizações, 0 empregador conquista uma ampla liberdade para ajustar o quantitativo da força de trabalho utilizada. Como nos aponta Krein (2007, p. 151), ele pode, por exemplo, substituir trabalhadores com mais tempo de empresa por outros mais novos, mais escolarizados e com salários inferiores; ou também pode manter em seu núcleo mais estável um número pequeno de trabalhadores e realizar contratações de acordo com a sazonalidade da demanda.

Outras medidas legais de precarização foram instituídas progressivamente. A Constituição de 1988 foi responsável por uma parte considerável delas. Martins (2005, p. 40), analisa o processo como flexibilização do Direito do Trabalho e aponta que, a partir dessa Constituição tornou-se possível a redução dos salários de acordo com a convenção ou o acordo coletivo (art. 7º, VI); a compensação ou a redução da jornada de trabalho com redução de salário também se tornaram legais, desde que feitas mediante acordo ou convenção coletiva (art. 7º XIII); 0 aumento da jornada de trabalho nos turnos ininterruptos de revezamento para mais de seis horas diárias passou também pela intermediação da negociação coletiva.

Outra forma de precarização do trabalho - lembremo-nos que a maioria dos autores trata como flexibilização - foi a instituiç̧ão da PLR (Participação nos 
Lucros e Resultados) pelo governo de Itamar Franco com a Medida Provisória (MP) 794, de setembro de 1994. A PLR altera a forma de remuneração do trabalhador, pois se trata de uma forma de remuneração variável, sobre a qual não incidem encargos sociais e que, portanto, não é incorporada ao salário e nem à aposentadoria. Ademais, a PLR incita ao individualismo e ao corporativismo ao estimular o engajamento do trabalhador nos objetivos da empresa, a vigilância entre si dos trabalhadores e a concorrência entre os trabalhadores de diferentes empresas de um mesmo setor econômico.

Segundo Galvão (2007), o governo de Fernando Henrique Cardoso promoveu uma extensa reforma precarizante, que pode ser dividida em três frentes fundamentais:

1) as formas de contratação: foram introduzidas formas consideradas atípicas ou, melhor dizendo, precárias de contratação, como a extensão do contrato de trabalho por prazo determinado para qualquer setor ou ramo de atividade (modalidade de contratação que, findo o contrato, não proporciona ao trabalhador o pagamento de verbas rescisórias), o contrato em tempo parcial (máximo de 25 horas semanais, com correspondente redução de salário, encargos e direitos), a suspensão do contrato de trabalho por um período de 2 a 5 meses (estratégia que retira 0 trabalhador com contrato suspenso das estatísticas de desemprego, mas que não lhe assegura o retorno ao trabalho ao término da suspensão, uma vez que pode ser demitido). 2) as formas de resolução de conflitos: a introdução das comissões de conciliação prévia atribui a uma instância privada (pois constituída no âmbito da empresa ou do sindicato) o poder de dirimir conflitos entre empregado e empregador, e de celebrar acordos que só são passíveis de reclamação na Justiça do Trabalho caso haja ressalvas explícitas quanto a itens não acordados, o que vem ensejando denúncias relativas a direitos lesados. 3) o tempo de trabalho: a introdução do banco de horas possibilita a anualização da jornada. As horas excedentes de trabalho não são remuneradas como hora extra, mas sim depositadas numa conta e compensadas com redução da jornada em períodos de baixa atividade ou com folga ao longo do ano, conforme cronograma estabelecido pela empresa. A abertura do comércio aos domingos é outra medida que vem desorganizar a vida do trabalhador, uma vez que ele não tem controle sobre sua escala de trabalho (GALVÃo, 2007, p. 4-5).

Seguindo a linha argumentativa de uma parte dos autores da área do Direito do Trabalho, Martins (2005, p. 38) afirma que a "flexibilização dos direitos do trabalho", como um conjunto de regras que tem por objetivo instituir mecanismos de compatibilização com as mudanças de ordem econômica, tecnológica ou social 
existentes na relação entre o capital e o trabalho, é uma teoria que surgiu para adaptar 0 Direito ao dinamismo da realidade. E isso se faz, segundo o autor, mudando-se a legislação, não a eliminando. Embora não concordemos com o diagnóstico dos efeitos da chamada "flexibilização" feito pelo autor - onde uma das principais conclusões é a de que os trabalhadores também são beneficiários do processo - é preciso reconhecer que sua análise lança uma luz importante para a discussão de mais uma de nossas palavras-chave: desregulamentação. Segundo o autor,

Flexibilizar não tem, portanto, por sinônimo, desregulamentar, pois épossível, inclusive, flexibilizar por meio da legislação, como o faz a Constituição (art. 7º, VI, XIII e XIV). Consiste a flexibilização exatamente em menor rigidez da legislação, propiciando adaptações no trabalho, em razão das modificações sociais e econômicas (MARTINS, 2005, p. 40).

Ou seja, desregulamentar, tal como usamos hoje nas ciências sociais e como usa o próprio movimento operário, tem significado, no geral, reduzir os direitos trabalhistas. Também denomina um processo muito maior no sentido de regulamentar o trabalho de uma nova forma - adaptada às necessidades da reestruturação produtiva da empresa capitalista e às políticas neoliberais - do que a supressão de leis protetoras. Isto posto, concluímos novamente que, como indicativo de um movimento, é mais apropriado substituir o uso do termo "desregulamentação", por expressões como "redução de direitos" ou "precarização do direito e das proteções ao trabalho" ou "nova regulamentação precarizante".

Precarização não é exatamente um conceito. Também não é um indicador (como é o desemprego, por exemplo). É, outrossim, um termo que indica um movimento cujo parâmetro de comparação são as conquistas operárias do período do Estado de bem-estar social nos países de capitalismo desenvolvido, ou ainda do desenvolvimentismo de alguns países de capitalismo dependente, caso do Brasil no período populista (1930 a 1964). Reconhecemos que usar o termo "precarização" revela uma dificuldade de comparação com a ajuda de indicadores sistemáticos, tendo em vista, principalmente, as particularidades institucionais de cada país. A palavra precarização está associada às idéias de instabilidade, de provisório, de fragilidade, de incerteza; todas palavras que remontam ao padrão de exploração capitalista anterior aos pós-guerras e que ganham novos significados com as condições de trabalho que vêm sendo desenhadas desde o início da década de 1970.

No Brasil, o termo precarização não resulta na designação de um grupo social específico, os precarizados. Na França esse mapeamento do que é trabalho 
precarizado é mais sistemático e serve como ponto de apoio para políticas públicas. ${ }^{6}$ 0 governo consegue rastrear o número de contratos considerados precários e as empresas que os utilizam ${ }^{7}$. Em 1998, Lionel Jospin, então primeiro ministro da França, pretendeu punir as empresas que possuíssem nos seus efetivos de 10 a 15\% de trabalhadores precários (tais como na indústria automobilística, na agricultura e na construção civil). Naquele país, trabalho precário é considerado aquele que não supre as necessidades do trabalhador e de sua família e que não lhe permite se proteger no futuro.

Segundo Lebaron (2000, p. 750), os dados que alguns autores usam hoje como indicadores dos efeitos do desemprego e da precarização do trabalho eram utilizados, há trinta anos, como indicadores de pobreza: endividamento, fragilidade de rendimentos, queda no nível de vida, etc. Ou seja, a categoria "pobreza" teria sofrido uma transformação com o neoliberalismo que a teria deixado mais palatável. Assim, deixar-se-ia de lutar contra a pobreza e passar-se-ia a lutar contra a exclusão e a precarização. A pobreza seria um resíduo necessário e a existência dos pobres não passaria de um resultado menor da ação econômica modernizadora. As ações contra a pobreza passam a ser entendidas como custos que pesam sobre o orçamento do Estado. São, do ponto de vista da doxa neoliberal, ações de solidariedade exteriores à ação econômica. Precarização seria, portanto, um eufemismo para falar de um processo que é, na verdade, de pauperização das classes trabalhadoras.

A crítica de Lebaron não nos parece infundada, mas, na nossa compreensão, deixa de levar em consideração a história do modo de produção capitalista e as conquistas dos trabalhadores num determinado período dela; pelo menos na parcela dos países onde as condições de trabalho tiveram melhoras significativas com as políticas de bem-estar social. ${ }^{8}$ Esse parâmetro de comparação nos parece

\footnotetext{
${ }^{6}$ Perrin (2004, p. 1) assim define o termo "precarização": "compreende-se por precarização o conjunto das formas atípicas de emprego, essencialmente os contratos por tempo determinado e o trabalho temporário, mas igualmente os contratos de qualificação e adaptação, e mesmo as formas de emprego que não asseguram um rendimento igual ao SMIC [Salaire minimum interprofessionnel de croissance], a saber, principalmente os contratos por tempo indeterminado em tempo parcial sem a opção de escolha por jornada completa." (PERRIN, 2004, p. 1).

${ }^{7}$ Em meados dos anos 1990, 8\% do total da população francesa estava empregada de forma precária. A precarização era passagem obrigatória para o ingresso no mercado de trabalho. Em 1980, 8\% dos jovens estavam nessa situação e em 1990, mais de 18\% (LALLEMENT, 2000). ${ }^{8} 0$ impacto do medo da pobreza nos parece uma explicação plausível para o fato de ter se
} 
importante, inclusive para as disputas que se travam hoje em busca da reversão ou redução da precariedade dos empregos e das relações de trabalho.

\section{EM SÍNTESE}

Para concluir, façamos uma breve síntese do que entendemos da utilização de cada um dos termos:

a) flexibilização: seu uso é completamente inadequado quando se refere às relações de contrato e emprego. 0 que parte da literatura da área de trabalho convencionou chamar de flexibilização dos direitos dos trabalhadores é, na verdade, redução desses direitos. Entretanto, nos parece adequado entender que os processos produtivos estão, de fato, mais flexíveis. Essa flexibilidade é dada pela possibilidade de adequação da produção à demanda através do aumento ou diminuição de máquinas e trabalhadores, pela polivalência imposta a eles, pelas mudanças qualitativas inseridas constantemente por sugestão dos trabalhadores, entre outros fatores. Essas inovações da reestruturação produtiva da empresa capitalista representam uma flexibilização das formas de produção e gestão fordistas. Como apontamos, esse processo de flexibilização dos processos produtivos resultou, até o momento, e principalmente para os trabalhadores brasileiros, num incremento, dentro dos locais de trabalho, do processo geral de precarização. Com isso, definimos o uso do segundo termo.

b) precarização: como sinônimo de um processo, pode e deve ser usado para qualificar as mudanças nas relações de trabalho e emprego ocorridas desde a crise do capitalismo da década de 1970. 0 termo precarização é qualificativo apropriado para 1) as conseqüências para os trabalhadores da redução dos direitos trabalhistas e da nova forma de atuação do Estado nesta matéria, bem como no oferecimento de mecanismos de proteção social; e 2) as conseqüências para os trabalhadores da inserção de novas tecnologias, da reorganização do espaço e das hierarquias das empresas, da necessidade da polivalência, da introdução de mecanismo de variação salarial e da incorporação de variadas funções (como controle de qualidade e limpeza) àquela principal do trabalhador.

c) trabalho atípico: 0 adjetivo atípico sugere tratar-se de algo excepcional. Por isso, o seu uso é impróprio, pois o termo se refere, na verdade, a situações

tornado um apelo forte do sindicalismo francês a luta contra a existência do que eles chamam de "trabalhador pobre". 
muito correntes no capitalismo contemporâneo, principalmente nos países que não conheceram um Estado de bem-estar. 0 uso do termo "trabalho atípico" não redunda propriamente em erro se tal expressão for utilizada, explicitamente, para contrastar com o tipo de contrato de trabalho que ficou estabelecido como padrão pela legislação brasileira: contrato assinado na carteira profissional, por tempo indeterminado, com jornada regular e integral. Entretanto, dada a proporção do que se poderia chamar de "trabalho atípico" no Brasil", acreditamos que, mesmo com essa ressalva, o seu uso pode gerar mal-entendidos e ser considerado inadequado.

d) desregulamentação: termo pouco preciso, que deve ser evitado. 0 processo ao qual ele se refere é o de mudanças na legislação que reduzem, na prática, os direitos e as proteções sociais e do trabalho. Entretanto, não há extinção pura e simples de leis, mas modificações na legislação existente. Para caracterizar esse processo, sugerimos o uso dos termos "redução dos direitos trabalhistas" - e sociais, se for o caso - ou "nova regulamentação precarizante".

\section{REFERÊNCIAS}

AMORIM, Elaine Regina Aguiar. No limite da precarização? terceirização e trabalho feminino na indústria de confecção. 2003. 245 p. Dissertação (Mestrado em Sociologia) - Universidade Estadual de Campinas, Campinas.

ANTUNES, Ricardo. Os sentidos do trabalbo: ensaio sobre a afirmação e a negação do trabalho. São Paulo: Boitempo, 1999.

ARAÚJO, Ângela Maria Carneiro. 0 sindicalismo brasileiro na encruzilhada: desafios e mudanças recentes. Revista Latinoamericana de Estudios del Trabajo, Buenos Aires, v. 1, n. 4, p. 217-250, 2007.

ARBIX, Glauco. Trabalho: dois modelos de flexibilização. Lua Nova, São Paulo, n. 37, p. 171-190, 1996.

BIHR, Alain. 0 pós-fordismo: realidade ou ilusão? Mosaico, Vitória, v. 1, n. 2, p. 209-228, 1999.

\footnotetext{
${ }^{9}$ Dados do Dieese mostram que, no ano de 2006,36,5\% dos trabalhadores brasileiros empregados não tinham carteira de trabalho assinada (DIEESE, 2008). Ainda é preciso considerar que entre os $63,5 \%$ dos trabalhadores empregados que possuem carteira de trabalho assinada estão várias formas de contrato precarizado, tais como: tempo determinado, tempo parcial, etc.
} 
BRAGA, Ruy. A restauração do capital: um estudo sobre a crise contemporânea. São Paulo: Xamã, 1996.

CAVALCANTE, Sávio. Sindicalismo e privatização das telecomunicações. São Paulo: Expressão Popular, 2009.

CORIAT, Benjamin. Pensar pelo avesso. Rio de Janeiro: Revan, 1994.

DIEESE - Departamento Intersindical de Estatística e Estudos Socioeconômicos. Anuário dos trabalhadores. 2008. Disponível em: <http://www.mte.gov.br/ dados_estatisticos/anuario_2008/arquivos/pdf/anuario_trabalhadores_2008. pdf > . Acesso em: 4 fev. 2011

DRUCK, Maria da Graça; BORGES, Ângela. Terceirização: balanço de uma década. Caderno CHR, Salvador, n. 37, p. 111-139, jul./dez. 2002.

DRUCK, Maria da Graça. Terceirização: (des) fordizando a fábrica: um estudo do complexo petroquímico. São Paulo: Boitempo, 1999.

FILGUEIRAS, Luiz. 0 neoliberalismo no Brasil: estrutura, dinâmica e ajuste do modelo econômico. In: BASUALDO. Eduardo; ARCE0, Enrique (Org.). Neoliberalismo y sectores dominantes: tendências globales y experiências nacionales. Buenos Aires: CLACSO, 2006. p. 179-206. Disponível em: <http:// bibliotecavirtual.clacso.org.ar/ar/ libros/grupos/basua /C05 Filgueiras.pdf>. Acesso em: 11 dez. 2007.

FLEURY, Afonso. Novas tecnologias, capacitação tecnológica e processo de trabalho: comparações entre o modelo japonês e o modelo braisleiro. In: HIRATA, Helena (Org.). Sobre o modelo japonês. São Paulo: Edusp, 1993. p. 33-47.

GALVÃO, Andréia. Neoliberalismo e reforma trabalbista no Brasil. Rio de Janeiro: Revan, 2007.

GOUNET, Thomas. Fordismo e toyotismo na civilização do automóvel. São Paulo: Boitempo, 1999.

KREIN, José Dari. As formas de contratação flexível no Brasil. In:

Tendências recentes nas relações de emprego no Brasil: 1990-2005. 2007. 319 p. Tese (Doutorado em Economia Aplicada) - Universidade Estadual de Campinas, Campinas. (Capitulo 2).

LALLEMENT, Michel. Les paradigmes de la flexibilité en France: des régulations aux "mondes vécus". Mana, Caen, n. 7, p. 203-220, 2000.

LEBARON, Frédéric. Chômage, precarité, pauvreté: quelques remarques sur la définition sociale des objectifs de politique économique. Regards Sociologiques, Strasbourg, n. 21, p. 67-78, 2000. 
LEITE, Márcia de Paula. Trabalho e sociedade em transformação. Sociologias, Porto Alegre, ano 2, n. 4, p. 66-87, 2000.

LIMA, Jacob Carlos. Desconcentração industrial e precarização do trabalho: cooperativas de produção do vestuário no Brasil. In: INTERNATIONAL CONGRESS LATIN AMERICAN STUDIES ASSOCIATION, 1998, Chicago. Anais... Chicago, 1998. (Mimeo)

LINHART, Danièle; RIST, Barbara; DURAND, Estelle. Perte d'emploi, perte de soi. Ramonville: Saint-Agne, 2002.

LORENZ0, Francine. Salário mínimo deveria ser de $\mathrm{R} \$ 2.227,53$, diz Dieese. De Valor On Line. 2011. Disponível em: <http://www.valoreconomico.com.br/ online/indicadores $\quad / 10 / 366813 /$ salario-minimo-deveria-ser-de-r-222753-dizdieese >. Acesso em: 4 fev. 2011.

MARCELINO, Paula Regina Pereira. A logística da precarização: terceirização do trabalho na Honda do Brasil. São Paulo: Expressão Popular, 2004.

. Terceirização e ação sindical: a singularidade da reestruturação do capital no Brasil. 2008. 373 p. Tese (Doutorado em Ciências Sociais) - Universidade Estadual de Campinas, Campinas.

MARTINS, Sérgio Pinto. A terceirização e o direito do trabalho. 7. ed. São Paulo: Atlas, 2005.

NANTEIUL, Matthieu de. Vers de nouvelles formes de vulnérabilité sociale? reflexion sur les rapports entre flexibilité et précarité. Travail et Emploi, Paris, n. 89, p. 6580, jan. 2002.

OLIVEIRA, Marco A. Terceirização: estruturas e processos em cheque nas empresas. São Paulo: Nobel, 1994.

PAGNONCELLI, Dernizo. Terceirização e parceirização: estratégias para o sucesso empresarial. Rio de Janeiro: D. Pagnoncelli, 1993.

PERRIN, Evelyne. Syndicats et collectifs face à la precarité. 2004. Disponível em: $<$ www.iscra.org/fichier.php?id=62> . Acesso em: 20 dez. 2006.

POCHMAN, Márcio. Sindeepres 15 anos: a superterceirização dos contratos de trabalho. 2007. 31 p. Disponível em: <http://www.sindeepres.org.br/ v01/index/ Pesquisa\%20Marcio\%20Pochman.pdf> . Acesso em: 29 jul. 2007.

SALLUM JUNIOR, Brasílio. O Brasil sob cardoso: neoliberalismo e desenvolvimentismo. Tempo Social, São Paulo, v. 11, n. 2, p. 23-47, 1999.

VASAPOLLO, Luciano. O trabalho atípico e a precariedade. São Paulo: Expressão Popular, 2005. 